Published in final edited form as:

Psychiatry Res. 2014 January 30; 215(1): 52-60. doi:10.1016/j.psychres.2013.10.006.

\title{
Functional development in clinical high risk youth: Prediction of schizophrenia versus other psychotic disorders
}

\author{
Sarah I. Tarboxa, ${ }^{\mathrm{*}}$, Jean Addington ${ }^{\mathrm{b}}$, Kristin S. Cadenhead ${ }^{\mathrm{c}}$, Tyrone D. Cannon ${ }^{\mathrm{d}}$, Barbara A. \\ Cornblatt $^{\mathrm{e}, \mathrm{f}, \mathrm{g}}$, Diana O. Perkins ${ }^{\mathrm{h}}$, Larry J. Seidman ${ }^{\mathrm{i}}$, Ming T. Tsuang ${ }^{\mathrm{j}, \mathrm{k}}$, Elaine F. Walker', \\ Robert Heinssen $^{\mathrm{m}}$, Thomas H. McGlashan ${ }^{\mathrm{a}}$, and Scott W. Woods ${ }^{\mathrm{a}}$ \\ aYale University School of Medicine, Department of Psychiatry, New Haven, Connecticut, 06519, \\ USA \\ bUniversity of Calgary, Department of Psychiatry, Calgary, Alberta, Canada \\ cUniversity of California, San Diego, Department of Psychiatry, La Jolla, California, 92093, USA \\ dUniversity of California, Los Angeles, Department of Psychology, Los Angeles, California, 90095, \\ USA
}

eThe Zucker Hillside Hospital, Psychiatry Research, North Shore - Long Island Jewish Health System, Glen Oaks, New York, 11004, USA

${ }^{f}$ Albert Einstein College of Medicine, Department of Psychiatry, Bronx, NY, 10461, USA

9The Feinstein Institute for Medical Research, North Shore - Long Island Jewish Health System, Manhasset, New York, 11030, USA

hUniversity of North Carolina at Chapel Hill, Department of Psychiatry, Chapel Hill, North Carolina, 27599, USA

'Harvard Medical School, Departments of Psychiatry at Massachusetts Mental Health Center Public Psychiatry Division, Beth Israel Deaconess Medical Center, and Massachusetts General Hospital, Boston, Massachusetts, 02115, USA

JUniversity of California, San Diego, Center for Behavioral Genomics, Department of Psychiatry, La Jolla, California, 92037, USA

kHarvard Institute of Psychiatric Epidemiology and Genetics, Boston, Massachusetts, 02115, USA

'Emory University, Department of Psychology, Atlanta, Georgia, 30322, USA

mNational Institute of Mental Health, Division of Adult Translational Research and Treatment Development, Bethesda, Maryland, 20892, USA

\section{Abstract}

This study evaluates premorbid social and academic functioning in clinical high-risk individuals as predictors of transition to schizophrenia versus another psychotic disorder. Participants were 54

(C) 2013 Elsevier Ireland Ltd. All rights reserved

"Correspondence concerning this paper should be addressed to: Sarah I. Tarbox, Ph.D. Department of Psychiatry Yale University School of Medicine Connecticut Mental Health Center 34 Park Street, 38D New Haven, CT 06519 USA sarah.tarbox@yale.edu Phone: 203-974-7050 Fax: 203-974-7057.

Publisher's Disclaimer: This is a PDF file of an unedited manuscript that has been accepted for publication. As a service to our customers we are providing this early version of the manuscript. The manuscript will undergo copyediting, typesetting, and review of the resulting proof before it is published in its final citable form. Please note that during the production process errors may be discovered which could affect the content, and all legal disclaimers that apply to the journal pertain. 
individuals enrolled in phase one of the North American Prodrome Longitudinal Study who over two and a half years of follow-up met criteria for schizophrenia/schizophreniform disorder ( $n=$ 28 ) or another psychotic disorder $(n=26)$. Social and academic functioning in childhood, early adolescence, and late adolescence was assessed at baseline using the Cannon-Spoor Premorbid Adjustment Scale. Social maladjustment in late adolescence predicted significantly higher odds of transition to schizophrenia versus another psychotic disorder independent of childhood and early adolescent adjustment $(O R=4.02)$ and conveyed unique risk over academic maladjustment $(\mathrm{OR}=$ 5.64). Premorbid academic maladjustment was not associated with psychotic disorder diagnosis. Results support diagnostic specificity of premorbid social dysfunction to schizophrenia in clinical high-risk youth and underscore an important role for social maladjustment in the developmental pathology of schizophrenia and its prediction.

\section{Keywords}

Adolescence; Diagnosis; Premorbid; Prodrome; Prospective; Psychosis; Social Adjustment

\section{Introduction}

Of all psychotic disorders, individuals with schizophrenia experience exceptionally severe and disabling symptoms, limited benefit from available treatments, and restricted independence of living (Bora et al., 2009). If meaningful differences between schizophrenia and other psychoses can be detected prior to the onset of psychosis, this information could aid in earlier identification and treatment of individuals at risk for a particularly severe course of illness (i.e., schizophrenia).

Poor premorbid social functioning is a core feature of schizophrenia (Kraepelin, 1919) and may be promising as an early risk marker for schizophrenia psychosis. Many schizophrenia patients experience a substantial decline in social functioning before their first psychotic episode, including withdrawal from family and peers, suspiciousness, and difficulty communicating (Haas and Sweeney, 1992; MacBeth and Gumley, 2008). The level of social functioning attained prior to psychosis onset is also an important correlate of individual variation in illness characteristics, course, and outcome in schizophrenia (Bromet et al., 1974). For example, deteriorating or chronically poor functioning prior to the onset of schizophrenia psychosis is strongly associated with earlier age of psychosis onset, greater severity and treatment refraction of negative symptoms, greater cognitive deficits, and poorer quality of life (Haas and Sweeney, 1992; Bailer et al., 1996; Larsen et al., 1996; Levitt et al., 1996; Addington et al., 2003; Silverstein et al., 2003; Strous et al., 2004; Addington and Addington, 2005; Haim et al., 2006). In addition, premorbid social dysfunction in schizophrenia is typically much more severe and pervasive than functional deficits observed in patients with psychotic mood disorders, patients with non-psychotic psychiatric disorders, non-psychotic siblings of schizophrenia patients, and controls (Strauss and Carpenter, 1972; Cannon et al., 1997; Mueser and Bellack, 1998; Willinger et al., 2001; McClellan et al., 2003; Uzelac et al., 2006). Recent evidence also supports greater premorbid functional deficits in schizophrenia patients compared to patients with schizoaffective disorder, at least in late adolescence (Uzelac et al., 2006; Saracco-Alvarez et al., 2009; Tarbox et al., 2012). This suggests possible diagnostic specificity to schizophrenia even among psychotic disorders, including those in the "schizophrenia-spectrum".

Given the strong connection between premorbid social functioning and schizophrenia pathology, prospective identification of social dysfunction in childhood or adolescence could be informative for prediction of schizophrenia. Early social dysfunction as a marker of liability to schizophrenia is supported by prospective data from birth cohort (Done et al., 
1994; Jones et al., 1994; Davidson et al., 1999; Bearden et al., 2000; Rabinowicz et al., 2000; Cannon et al., 2002; Reichenberg et al., 2002), familial high-risk (Hans and Marcus, 1987; Olin et al., 1998; Amminger et al., 1999; Carter et al., 2002; Schiffman et al., 2004; Johnstone et al., 2005; Niemi et al., 2005), psychometric high-risk (Kwapil, 1998), and casecontrol follow-back (Watt, 1978; Cannon et al., 2001) samples. Association between social dysfunction and future psychosis is also gaining support from prospective research with clinically identified high-risk youth [i.e., presenting with sub-threshold "psychotic-like" positive symptoms indicative of elevated risk for developing a psychotic disorder (Miller et al., 2003; Woods et al., 2009; McGlashan et al., 2010)]. These individuals, typically referred to as "clinical high-risk" (CHR) or "ultra high-risk" (UHR) in the literature, endorse significantly greater difficulties in social and role functioning at baseline compared to same age non-high-risk controls (Lencz et al., 2004; Cornblatt et al., 2007; Pinkham et al., 2007; Addington et al., 2008; Woods et al., 2009; Corcoran et al., 2011). Furthermore, poor functioning and persistent negative symptoms are among the few predictor variables to make a significant, independent contribution to prediction of psychosis in CHR youth (Yung et al., 2003; Mason et al., 2004; Yung et al., 2004; Cornblatt et al., 2011; Dragt et al., 2011; Piskulic et al., 2012), over and above other indicators of risk including positive psychoticlike symptoms (Cannon et al., 2008; Velthorst et al., 2009; Ruhrmann et al., 2010; Thompson et al., 2011; Cornblatt et al., 2012).

In this area of research, baseline functioning of CHR youth has been a primary focus to date. In contrast, only a few studies have examined developmental course of functioning prior to enrollment in a CHR study. Reports from the Dutch Prediction of Psychosis Study (DUPS) (Carr et al., 2000) suggest a possible correlation between deterioration of functioning from childhood to early adolescence and subsequent transition to psychosis in high-risk youth (Mason et al., 2004; Dragt et al., 2011). A pattern of early functional deterioration among CHR individuals is also consistent with results from phase one of the North American Prodrome Longitudinal Study (NAPLS-1) (Addington et al., 2008; Woods et al., 2009), including recent evidence that poor social adjustment in adolescence predicts transition to psychosis in NAPLS-1 CHR youth (Tarbox et al., 2013).

The current study follows from and extends this recent investigation by Tarbox and colleagues. Briefly, Tarbox et al. (2013) examined social and academic maladjustment in childhood, early adolescence, and late adolescence (Cannon-Spoor Premorbid Adjustment Scale ratings) in 270 CHR subjects in the NAPLS-1 dataset. Seventy-eight of these CHR individuals transitioned to psychosis during the two and a half year follow-along period, and results indicated that early adolescent social maladjustment was a significant predictor of psychosis $(H R=1.30, P=0.014)$ over and above childhood social dysfunction and independent of baseline severity of most positive and negative psychosis-risk symptoms. Early adolescent social maladjustment also demonstrated moderate positive predictive power (46\%) and high specificity (72.1\%) in predicting psychosis. In contrast, deterioration of academic functioning was observed in CHR youth, but did not predict transition to psychosis.

These findings are consistent with the substantial evidence that poor premorbid social functioning is an important antecedent of schizophrenia. However, specificity of premorbid social dysfunction to schizophrenia-related psychosis has not been tested in NAPLS-1 or in any other CHR sample. Thus, it is unknown if social dysfunction in CHR youth predicts transition to schizophrenia in particular, or predicts psychosis onset more broadly.

The primary aim of the current study is therefore to determine if social maladjustment in childhood, early adolescence, and/or late adolescence predicts schizophrenia versus nonschizophrenia psychosis in CHR youth who develop a psychotic disorder. Prediction of 
outcome diagnosis is also examined for premorbid academic functioning. The current study tests the following hypotheses: 1) premorbid social dysfunction in CHR youth predicts greater odds of transition to schizophrenia compared to odds of another psychotic disorder, 2) premorbid academic dysfunction does not predict outcome diagnosis of schizophrenia versus another psychotic disorder, and 3) premorbid social dysfunction predicts transition to schizophrenia versus other psychotic disorders over and above the effects of academic dysfunction.

\section{Method}

\subsection{Participants}

The current study utilized data from phase one of the North American Prodrome Longitudinal Study (NAPLS-1), a collaboration of eight independently conceived, NIMHfunded projects focused on prospectively examining psychosis-risk factors and improving prediction. These projects were granted supplements to create a federated database, and each site obtained IRB approval to contribute anonymous data. The construction of the database has been described previously (Addington et al., 2007).

The NAPLS- 1 database consists of data for 860 non-psychotic individuals enrolled across the eight sites between 1998 and 2005. Of this sample, 377 individuals met Criteria for Prodromal Syndromes outlined in the Structured Interview for Psychosis-risk Syndromes (SIPS). A diagnosis of psychosis-risk (prodromal) syndrome requires that one or more of the following criteria are met: (1) new onset or recent worsening of sub-threshold ("attenuated") positive psychotic symptoms (APS), (2) very brief periods of fully psychotic positive symptoms (BIPS), or (3) deterioration in functioning within the last year and having either schizotypal personality disorder or a first degree relative with psychosis (GRD) (Miller et al., 2002; Miller et al., 2003; Hawkins et al., 2004; Lencz et al., 2004; Lemos et al., 2006; McGlashan et al., 2010). The database was closed to follow-up data after September 30, 2006.

2.1.1 Current study-Selection for the current study required that all four of the following inclusion criteria were met: 1) psychosis-risk symptoms at baseline, 2) onset of psychosis during the two and a half-year follow-along period of NAPLS-1,3) psychotic disorder diagnosis established using Diagnostic and Statistical Manual of Mental Disorders, 4th Edition (DSM-IV) or Diagnostic and Statistical Manual of Mental Disorders, 4th Edition, Text Revision (DSM-IV-TR) criteria (American Psychiatric Association, 1994, 2000) based on a structured diagnostic interview [e.g., Structured Clinical Interview for DSM-IV (SCID-I) (First et al., 1995)], and 4) availability of Premorbid Adjustment Scale (PAS) (Cannon-Spoor et al., 1982) data for childhood, early adolescence, and late adolescence.

\subsection{Assessment}

2.2.1 Psychosis-risk symptoms and syndrome diagnosis-The SIPS and the Scale of Prodromal Symptoms (SOPS) contained within the SIPS interview were administered at baseline to evaluate positive, negative, disorganized, and general psychosisrisk symptoms and diagnose psychosis-risk syndrome. SOPS symptoms are rated on a 0-6 scale with extensive anchors for each scale point for each symptom. For positive symptoms, the anchor title for a rating of zero is "none" and for a rating of six is "psychotic."

After baseline, SOPS symptom severity ratings were reassessed every 6 months up to 30 months or until psychosis onset. Baseline and follow-up SIPS/SOPS interviews were conducted by trained masters or doctoral level interviewers who met local reliability 
standards and were under the supervision of the investigators. Diagnostic agreement with gold standard SIPS diagnoses was in the excellent range (kappa >0.80) at each center (Addington et al., 2007). Psychosis-risk symptom ratings and diagnoses were verified through consensus diagnosis meetings by senior clinicians and trained interviewers. Detailed descriptions of SIPS symptom severity scales and psychometric properties are available (Miller et al., 2002; Miller et al., 2003; Hawkins et al., 2004; Lencz et al., 2004; Lemos et al., 2006; McGlashan et al., 2010).

2.2.2 Baseline co-morbid psychiatric disorders-Lifetime and co-morbid axis I psychiatric diagnoses were established at baseline using a structured diagnostic interview, primarily the SCID-I or the Schedule for Affective Disorder and Schizophrenia for SchoolAged Children (K-SADS) (Kaufman et al., 1997). Structured diagnostic interviews were conducted by trained interviewers, usually at the masters or doctoral level, and under the supervision of investigators.

2.2.3 Premorbid adjustment-The Premorbid Adjustment Scale (PAS) (Cannon-Spoor et al., 1982) was also administered during the NAPLS-1 baseline assessment. The PAS is an interviewer-administered rating schedule designed to retrospectively assess functioning, primarily social and academic maladjustment, prior to psychosis onset and has established predictive and concurrent validity (Brill et al., 2008). Four developmental periods are assessed: childhood (age 5-11), early adolescence (age 12-15), late adolescence (age 1618), and adulthood (age 19 and above). Items are interviewer-rated on a 0 to 6 scale, with higher ratings representing greater maladjustment. Social maladjustment, such as withdrawal and poor peer relationships, is rated for all four age periods and includes social-sexual maladjustment in late adolescence and adulthood. Academic maladjustment, such as poor scholastic performance and poor adaptation to school, is rated for childhood through late adolescence. PAS ratings were based on an interview with the participant. Interviewers were typically at the masters or doctoral level and were supervised by investigators.

The current analyses utilized social maladjustment and academic maladjustment mean PAS ratings for childhood, early adolescence, and late adolescence. Given participant age at baseline (mean age: 18.0), adult PAS ratings were not applicable for the majority of participants (68.8\%) and thus not included in analyses.

2.2.4 Psychotic disorder outcome diagnosis-Transition to psychosis was defined according to SIPS/SOPS criteria as the presence of positive symptoms of sufficient intensity that are either seriously disorganizing or dangerous or have been present for at least half the days in a month, at least an hour per day. Possibly transitioning cases were interviewed with the SOPS to establish the presence of symptoms at a psychotic-level of intensity and were also interviewed with the SCID-I to establish a specific psychotic disorder diagnosis based on DSM-IV/DSM-IV-TR criteria. Onset of psychosis was confirmed through consensus meetings by senior clinicians and trained interviewers. In the case of participants who transitioned to psychosis, but did not receive a SCID-I interview (in-person assessment was not feasible), DSM-IV/DSM-IV-TR psychotic disorder outcome diagnosis was considered missing. Participants without a DSM-IV/DSM-IV-TR outcome diagnosis were excluded from the current study.

\subsection{Analyses}

Demographic comparisons were accomplished using t-test, chi-square, and correlation analyses. Covariate selection required association $(P<0.100)$ with psychotic disorder outcome diagnosis (schizophrenia versus a non-schizophrenia psychotic disorder) and with PAS ratings in the total sample (combined outcome diagnosis groups). 
The association between premorbid maladjustment and psychotic disorder outcome diagnosis was examined primarily using logistic regression analysis. Ordinal predictors were centered at their median and dichotomous predictors were assigned values of $+1 / 2$ and $-1 / 2$ as recommended by Kraemer and Blasey (2004). First, crude univariate logistic regression analysis (logistic regression with one predictor) was conducted to examine the effect of median-centered, non-standardized mean PAS ratings of social and academic maladjustment at each age (childhood, early adolescence, and late adolescence) on outcome diagnosis, without accounting for maladjustment at previous age periods. A conservative threshold for significance was used to correct for multiple comparisons $[P<0.008(0.05 / 6$ univariate tests)].

Second, median-centered, standardized mean PAS ratings for childhood, early adolescence, and late adolescence were entered sequentially into a multivariate logistic regression model to estimate the effect of maladjustment at each developmental period on odds of schizophrenia versus odds of another psychotic disorder when maladjustment ratings for earlier age periods were set equal to their median value. The social adjustment and academic adjustment domains were again examined separately. Although a less powerful test under these conditions, analysis of change scores was also conducted to examine the effect of change in functioning from one age period to another. Two change scores were calculated (early adolescence rating minus childhood rating; late adolescence rating minus early adolescence rating) for the social and the academic domains. Effect on diagnostic outcome was estimated for each change score individually using univariate logistic regression analysis.

Third, multivariate logistic regression analysis was conducted to determine if premorbid social maladjustment predicts greater odds of transition to schizophrenia versus another psychotic disorder, over and above any effects of academic maladjustment (and controlling for previous age periods). Median-centered, standardized mean academic and social maladjustment ratings for each developmental period were entered together in successive steps of a multivariate logistic regression model. Specifically, academic and social maladjustment ratings for childhood were entered in step one, academic and social maladjustment ratings for early adolescence were added in step two, and late adolescence ratings were added in step three.

Fourth, maladjustment ratings identified as uniquely associated with conversion to schizophrenia versus other psychotic disorders were examined further to determine optimal rating threshold(s) for prediction of schizophrenia. Receiver operating characteristic (ROC) curve analysis was conducted to identify potential rating "cut-points" for dichotomization to maximize schizophrenia prediction. To evaluate the effect of potential cut-points on prediction of schizophrenia, sensitivity, specificity, positive and negative predictive power (PPP and NPP, respectively), and positive and negative likelihood ratios (LR+ and LR-, respectively) were calculated and univariate logistic regression and Area Under Curve (AUC) analyses were performed for each dichotomized predictor.

\section{Results}

\subsection{Sample characteristics}

Fifty-four individuals in the NAPLS-1 database met the inclusion criteria for the current study: 1) psychosis-risk symptoms at baseline, 2) onset of psychosis during the two and a half-year follow-along period of NAPLS-1, 3) psychotic disorder diagnosis established using DSM-IV or DSM-IV-TR criteria based on structured diagnostic interview, and 4) availability of PAS data for childhood, early adolescence, and late adolescence. Fifty of these 54 subjects met full diagnostic criteria for one or more psychosis-risk syndromes 
(APS, BIPS, and GRD) at baseline based on the SIPS/SOPS. Data from these 50 subjects also contributed to the larger "psychosis conversion" outcome group in Tarbox et al (2013). Four of the current 54 subjects met partial criteria (all but one criterion met) for APS and/or GRD psychosis-risk syndromes at baseline; these subjects did not contribute to Tarbox et al (2013). As the focus of the current paper is on conversion diagnosis rather than baseline diagnosis, all 54 individuals met criteria for inclusion in the present study.

3.1.1 Psychotic disorder diagnoses-The following mutually exclusive psychotic disorder outcome diagnoses were present in the study sample $(n=54)$ : schizophrenia/ schizophreniform disorder (28), schizoaffective disorder (5), bipolar I disorder with psychotic features (4), major depressive disorder (MDD) with psychotic features (1), delusional disorder (1), brief psychotic disorder (2), and psychotic disorder, nos (not otherwise specified) (13). For simplicity, the schizophrenia/schizophreniform diagnostic group $(n=28)$ hereafter is referred to as "schizophrenia". All psychotic disorder diagnoses other than schizophrenia/schizophreniform disorder were combined to form the "other psychoses" group $(n=26)$. By definition this is a heterogeneous group; however, variability of demographic attributes was not substantial.

3.1.2 Diagnostic outcome group comparisons-Demographic characteristics for the schizophrenia and other psychoses diagnostic groups are presented in Table 1. Diagnostic groups did not differ $(P \geq 0.100)$ on sex, race, baseline age, baseline education, prodrome duration, age at psychosis onset, years of education at onset, or parent education. These groups also did not differ on rates of co-morbid, non-psychotic axis I disorders present at psychosis onset: mood disorder, anxiety disorder, attention deficit hyperactivity disorder, alcohol abuse/dependence, cannabis abuse/dependence, and conduct/oppositional-defiant disorder. Other axis I disorders were either absent or occurred with insufficient frequency for comparison.

\subsection{Premorbid maladjustment ratings}

Unadjusted mean ratings for social and academic maladjustment are presented in Figures 1 and 2, respectively. In the total study sample (combined diagnostic groups), male participants received higher (more pathological) social maladjustment ratings for late adolescence compared to female participants $(t=2.36, P=0.022)$. Fewer years of education at baseline was associated with higher academic maladjustment ratings for early adolescence $(r=-0.31, P=0.030)$ and late adolescence $(r=-0.32, P=0.018)$. PAS ratings were not associated with baseline age, prodrome duration, age at psychosis onset, years of education at onset, parent education, or co-morbid, non-psychotic axis I disorders.

Although sex and years of education at baseline were associated with PAS ratings, these variables did not correlate with outcome diagnosis and were unlikely to confound analyses. Furthermore, any effects of these variables on PAS ratings may not necessarily be spurious. Thus, demographic variables were not included as covariates in primary logistic regression analyses. Effects of sex and education on regression models were explored in secondary analyses (entered in the model prior to childhood ratings).

\subsection{Premorbid maladjustment and psychotic disorder diagnosis}

3.3.1 Premorbid social maladjustment-Univariate logistic regression analysis was conducted to evaluate the association between social maladjustment at each developmental period and psychotic disorder outcome diagnosis, without controlling for previous developmental stages. Results suggested a trend-level association between late adolescent social maladjustment and outcome diagnosis of schizophrenia (versus a non-schizophrenia psychotic disorder) $[O R=1.80(95 \% C I=0.96-3.39), P=0.069]$. This association was not 
significant when correcting for multiple comparisons, however. Neither child nor early adolescent social maladjustment was associated with outcome diagnosis in univariate analyses [childhood: $O R=1.26, P=0.389$; early adolescence: $O R=0.80, P=0.615$ ].

The association between social maladjustment and psychotic disorder outcome diagnosis, controlling for effect of social maladjustment at previous developmental stages, was evaluated using multivariate logistic regression analysis. As presented in Table 2, results indicated that poor social adjustment in late adolescence was associated with fourfold greater odds of being diagnosed at with schizophrenia at psychosis onset compared to odds of a non-schizophrenia psychotic disorder diagnosis, over and above effects of child and early adolescent maladjustment (Step 3) $[O R=4.02$ (95\%CI $=1.15-14.06), P=0.029]$. Classification analysis indicated that this model correctly classified $64.6 \%$ of participants. Conversely, social maladjustment in early adolescence was not associated with odds of schizophrenia when accounting for childhood maladjustment (Table 2, Step 2) ( $O R=0.80$, $P=0.615$ ). When sex was included as a covariate (not shown in table), the association between late adolescent social maladjustment and schizophrenia (controlling for childhood and early adolescence) remained significant $[O R=3.80(95 \% C I=1.06-13.42), P=0.040]$; childhood and early adolescence remained non-significant [childhood: $O R=1.21, P=$ 0.488 ; early adolescence (controlling for childhood): $O R=0.75, P=0.533$ ]. Change score analysis likewise supported an increase social maladjustment between early and late adolescence, and this difference predicted greater odds of schizophrenia versus nonschizophrenia psychosis [OR $=3.39(95 \% C I=1.05-10.82), P=0.041]$. Difference between childhood and early adolescent social maladjustment ratings did not predict outcome diagnosis $(\mathrm{OR}=0.73, P=0.342)$.

Optimal threshold for predicting schizophrenia versus other psychoses based on PAS rating of social maladjustment in late adolescence was evaluated next. Four potential cut-points for dichotomization of late adolescent social maladjustment were identified. As can be seen in Table 3, a cut point of 2.0, with ratings $>2.0$ indicating a "positive" prediction of schizophrenia and ratings $\leq 2.0$ predicting a non-schizophrenia psychotic disorder, provided the strongest association with outcome $[O R=4.75(95 \% C I=1.50-15.00), P=0.008 ; A U C$ $=0.69(95 \% C I=0.54-0.83), P=0.019]$. Relative to other options, a cut-point of 2.0 achieved a good balance of true positives ( $\mathrm{PPP}=70.4 \%)$ and true negatives $(\mathrm{NPP}=66.7 \%)$ while maximizing both sensitivity (67.9\%) and specificity (69.2\%). However, taking prevalence into account, results did not support PAS-rated late adolescent social maladjustment as a comprehensive predictor of diagnostic outcome $(\mathrm{LR}+=1.20$; $\mathrm{LR}-=$ $0.46)$.

3.3.2. Premorbid academic maladjustment-Univariate logistic regression analyses of academic maladjustment in childhood, early adolescence, and late adolescence, not controlling for previous developmental stages, indicated no association with psychotic disorder outcome diagnosis. Difference in academic maladjustment between one epoch and another also did not predict outcome diagnosis.

Consistent with univariate analyses, multivariate logistic regression did not support an association between premorbid academic maladjustment in childhood, early adolescence, or late adolescence and odds of being diagnosed with schizophrenia versus another psychotic disorder at psychosis onset; model parameters are provided in Table 4. Results remained non-significant when education at baseline was included in the model [Childhood: $O R=$ $1.36, P=0.380$; Early adolescence (controlling for childhood): $O R=0.42, P=0.149$; Late adolescence (controlling for childhood and early adolescence): $O R=0.72, P=0.557$ ]. 


\subsubsection{Social maladjustment controlling for effects of academic maladjustment}

-The final set of analyses was conducted to determine if premorbid social maladjustment is associated with transition to schizophrenia, over and above any contribution of academic maladjustment. Results of this analysis are presented in Table 5. They indicate that social maladjustment in late adolescence predicted significantly greater odds of being diagnosed with schizophrenia at psychosis onset compared to odds of a non-schizophrenia psychotic disorder, over and above effects of poor academic functioning (and controlling for child and early adolescent maladjustment) (Step 3) $[O R=5.64(95 \% C I=1.43-22.34), P=0.014]$. This model (Table 5 , Step 3 ) correctly classified $74.5 \%$ of participants. Results were comparable when sex and education at baseline were included in the model (not shown in table) [Childhood social: $O R=1.17, P=0.638$; Early adolescence social (controlling for childhood): $O R=0.75, P=0.563$; Late adolescence social (controlling for childhood and early adolescence): $O R=5.15, P=0.026]$.

\section{Discussion}

The primary aim of this study was to determine the extent to which premorbid social maladjustment in childhood, early adolescence, and/or late adolescence predicts schizophrenia versus non-schizophrenia psychosis in clinical high-risk (CHR) individuals who developed a psychotic disorder during a two and a half-year follow-along period. Specific findings are as follows:

- Late adolescent social maladjustment predicted significantly greater (four-fold) odds of transitioning to schizophrenia versus odds of transitioning to another psychotic disorder, independent of child and early adolescent maladjustment.

- Academic maladjustment was not associated with psychotic disorder outcome diagnosis.

- Late adolescent social maladjustment predicted five-fold greater odds of transitioning to schizophrenia versus odds of transitioning to another psychotic disorder, over and above the effect of academic maladjustment.

\subsection{Functional deficits and prediction of psychotic disorder diagnosis}

Consistent with the first hypothesis, among CHR youth who transitioned to psychosis, increased severity of social maladjustment in late adolescence, over and above level of maladjustment in early adolescence, predicted significantly greater risk of developing schizophrenia compared to another psychotic disorder. In contrast, CHR youth who did not experience worse social adjustment in late adolescence relative to early adolescent adjustment were more likely to be diagnosed with a non-schizophrenia psychotic disorder. Consistent with the second hypothesis, results indicated that premorbid academic maladjustment is not differentially associated with outcome diagnosis of schizophrenia versus other psychotic disorders in CHR youth. Finally, when the effects of academic maladjustment were taken into account, late adolescent social dysfunction in CHR youth predicted odds of schizophrenia at more than five times that of other psychoses, which is consistent with our third hypothesis.

Evidence that premorbid late adolescent social maladjustment predicts significantly greater odds of schizophrenia over odds of non-schizophrenia psychosis, independent of academic maladjustment, supports and extends prior findings in CHR and other relevant samples. These results fit well with the substantial evidence that both social and academic functioning are disrupted in CHR youth and with previous indications that social dysfunction in particular predicts psychosis (Mason et al., 2004; Addington et al., 2008; Cannon et al., 2008; Cornblatt et al., 2011; Dragt et al., 2011; Cornblatt et al., 2012; Tarbox et al., 2013). 
Evidence of diagnostic specificity further suggests that previously observed associations between adolescent social dysfunction and broad outcome of psychosis may reflect the subset of CHR youth who transition specifically to schizophrenia. Premorbid functioning across psychotic disorders has also been examined in a few first-episode studies and results likewise indicate that premorbid social dysfunction in late adolescence is a specific antecedent of schizophrenia versus schizoaffective and psychotic mood disorders (Uzelac et al., 2006; Saracco-Alvarez et al., 2009; Tarbox et al., 2012). Of note, as in previous studies, current results do not suggest that social functioning by itself would be a useful tool for predicting schizophrenia. Rather, cumulative evidence indicates that adolescent social functioning contributes unique information about risk for schizophrenia and would be a useful component of a multivariate prediction algorithm (e.g., Cannon et al., 2008).

In conjunction with data from prospective birth cohort, high risk, and follow-back samples, evidence that premorbid social maladjustment predicts schizophrenia in CHR youth, independent of other domains of functioning, provides further convergent support that social dysfunction is a critical early correlate of schizophrenia pathology (Tarbox and Pogue-Geile, 2008). Furthermore, social dysfunction may be indicative of important premorbid differences in developmental pathology between schizophrenia and other psychoses. Specificity of premorbid social functional decline to schizophrenia is consistent with theories that social withdrawal and negative symptoms (e.g., social anhedonia, avolition) are central to the developmental pathophysiology of this disorder (Häfner et al., 1999; Hoffman, 2007; Piskulic et al., 2012) and that adolescence is a period of particular neurodevelopmental vulnerability to psychosis. As such, one could speculate that observed stability of premorbid social functioning in non-schizophrenia psychotic disorders reflects possible attenuation of harmful physiological processes (e.g., less disruption in synaptic pruning) compared to a progressive disease process leading to schizophrenia psychosis. Finally, irrespective of the connection between premorbid social dysfunction and schizophrenia pathophysiology, social dysfunction is a key symptom among CHR youth and logical target for intervention.

\subsection{Limitations}

Schizophrenia is the specific diagnosis of interest in the current study. Still, the small sample size of the schizoaffective disorder group $(n=5)$ precluded secondary examination of schizoaffective disorder as a separate outcome diagnosis. In this sample (keeping in mind the small number of schizoaffective diagnoses), late adolescent social maladjustment was on average significantly worse in participants who transitioned to schizophrenia [mean standardized rating $(\mathrm{z})=0.60$ ] versus schizoaffective disorder (mean $\mathrm{z}=-0.23 ; P=0.025$ ). Conversely, late adolescent ratings did not differ between schizoaffective disorder and other psychoses (mean $\mathrm{z}=0.22 ; P=0.180$ ).

Second, the "other psychoses" group is heterogeneous by definition, and it is possible that this diagnostic variability may have influenced results. Increased within-group variability would tend to make between-group differences more difficult to detect. If this is a factor, our results may underestimate the predictive association between premorbid maladjustment and schizophrenia.

Lastly, the decision to exclude CHR individuals who did not receive PAS ratings for late adolescence limited the focus of the current study to participants who sought services for prodromal symptoms after age 16. Later onset of prodromal symptoms has been associated with better premorbid adjustment, suggesting a possible sampling bias toward participants with more intact premorbid functioning. As such, current results may not apply to social and academic functioning in younger at-risk groups. 


\subsection{Conclusion}

The results of this study indicate that deterioration of premorbid social functioning from early to late adolescence predicts transition to schizophrenia versus transition to another psychotic disorder in CHR youth who develop psychosis, over and above effects of academic functioning. In contrast, premorbid academic maladjustment may be characteristic of clinical high-risk status, but is not indicative of schizophrenia relative to other psychotic disorders. Specificity of late adolescent social dysfunction to schizophrenia in CHR youth is consistent with accumulating evidence that poor social functioning is an early, sensitive, and potentially specific correlate of schizophrenia developmental pathology that can be detected prior to psychosis onset. This study thus supports prognostic sensitivity of premorbid social maladjustment to schizophrenia, suggests functional heterogeneity among psychotic disorders that antedates psychosis onset, and highlights the importance of both severity and developmental course in the characterization of premorbid functioning in psychotic disorders.

\section{Acknowledgments}

This work was supported by National Institute of Mental Health (U01 MH066134 to J.A., R01 MH060720 and K24 MH76191 to K.S.C., R01 MH065079 to T.D.C., R01 MH061523 to B.A.C., U01 MH066069 and P50 MH064065 to D.O.P, R01 MH065562 and P50 MH080272 to L.J.S., R21 MH075027 to M.T.T, R01 MH062066 to E.F.W., K05 MH01654 to T.H.M., U01 MH066160 to S.W.W.); Donaghue Foundation (to S.W.W.); and Eli Lilly and Co (study HGGF to T.H.M., J.A., D.O.P.).

\section{References}

Addington J, Addington D. Patterns of premorbid functioning in first episode psychosis: Relationship to 2-year outcome. Acta Psychiatrica Scandinavica. 2005; 112:40-46. [PubMed: 15952944]

Addington J, Cadenhead KS, Cannon TD, Cornblatt B, McGlashan TH, Perkins DO, Seidman LJ, Tsuang M, Walker EF, Woods SW, Heinssen R. North American Prodrome Longitudinal Study: a collaborative multisite approach to prodromal schizophrenia research. Schizophrenia Bulletin. 2007; 33:665-672. [PubMed: 17255119]

Addington J, Penn D, Woods SW, Addington D, Perkins DO. Social functioning in individuals at clinical high risk for psychosis. Schizophrenia Research. 2008; 99:119-124. [PubMed: 18023329]

Addington J, van Mastrigt S, Addington D. Patterns of premorbid functioning in first-episode psychosis: Initial presentation. Schizophrenia Research. 2003; 62:23-30. [PubMed: 12765739]

American Psychiatric Association. Diagnostic and Statistical Manual of Mental Disorders. 4th ed.. American Psychiatric Association; Washington, DC: 1994.

American Psychiatric Association. Diagnostic and Statistical Manual of Mental Disorders. 4th ed. American Psychiatric Association; Washington, DC: 2000. text revision

Amminger GP, Pape S, Rock D, Roberts SA, Ott SL, Squires-Wheeler E, Kestenbaum C, ErlenmeyerKimling L. Relationship between childhood behavioral disturbance and later schizophrenia in the New York high-risk project. American Journal of Psychiatry. 1999; 156:525-530. [PubMed: 10200729]

Bailer J, Brauer W, Rey ER. Premorbid adjustment as predictor of outcome in schizophrenia: Results of a prospective study. Acta Psychiatrica Scandinavica. 1996; 93:368-377. [PubMed: 8792907]

Bearden CE, Rosso IM, Hollister M, Sanchez LE, Hadley T, Cannon TD. A prospective cohort study of childhood behavioral deviance and language abnormalities as predictors of adult schizophrenia. Schizophrenia Bulletin. 2000; 26:395-410. [PubMed: 10885639]

Bora E, Yucel M, Pantelis C. Cognitive functioning in schizophrenia, schizoaffective disorder, and affective psychoses: meta-analytic study. The British Journal of Psychiatry. 2009; 195:475-482. [PubMed: 19949193]

Brill N, Reichenberg A, Weiser M, Rabinowicz J. Validity of the premorbid adjustment scale. Schizophrenia Bulletin. 2008; 34:981-983. [PubMed: 18032397] 
Bromet E, Harrow M, Kasl S. Premorbid functioning and outcome in schizophrenics and nonschizophrenics. Archives of General Psychiatry. 1974; 30:203-207. [PubMed: 4809928]

Cannon-Spoor H, Potkin S, Wyatt R. Measurement of premorbid adjustment in chronic schizophrenia. Schizophrenia Bulletin. 1982; 8:470-484. [PubMed: 7134891]

Cannon M, Jones P, Gilvarry C, Rifkin L, McKenzie K, Foerster A, Murray RM. Premorbid social functioning in schizophrenia and bipolar disorder: similarities and differences. American Journal of Psychiatry. 1997; 154:1544-1550. [PubMed: 9356562]

Cannon M, Jones PB, Murray RM. Obstetric complications and schizophrenia: historical and metaanalytic review. American Journal of Psychiatry. 2002; 159:1080-1092. [PubMed: 12091183]

Cannon M, Walsh E, Hollis C, Kargin M, Taylor E, Murray RM, Jones PB. Predictors of later schizophrenia and affective psychosis among attendees at a child psychiatry department. British Journal of Psychiatry. 2001; 178:420-426. [PubMed: 11331557]

Cannon TD, Cadenhead K, Cornblatt B, Woods SW, Addington J, Walker E, Seidman LJ, Perkins D, Tsuang M, McGlashan T, Heinssen R. Prediction of psychosis in youth at high clinical risk: A multisite longitudinal study in North America. Archives of General Psychiatry. 2008; 65:28-37. [PubMed: 18180426]

Carr V, Halpin S, Lau N, O'Brien S, Beckmann J, Lewin T. A risk factor screening and assessment protocol for schizophrenia and related psychosis. Australian and New Zealand Journal of Psychiatry. 2000; 34:170-180.

Carter JW, Schulsinger F, Parnas J, Cannon T, Mednick SA. A multivariate prediction model of schizophrenia. Schizophrenia Bulletin. 2002; 28:649-682. [PubMed: 12795497]

Corcoran CM, Kimhy D, Parrilla-Escobar MA, Cressman VL, Stanford AD, Thompson J, Ben David S, Crumbley A, Schobel S, Moore H, Malaspina D. The relationship of social function to depressive and negative symptoms in individuals at clinical high risk for psychosis. Psychological Medicine. 2011; 41:251-261. [PubMed: 20444306]

Cornblatt BA, Auther AM, Neidham T, Smith CW, Zinberg J, Bearden CE, Cannon TD. Preliminary findings for two new measures of social and role functioning in the prodromal phase of schizophrenia. Schizophrenia Bulletin. 2007; 33:688-702. [PubMed: 17440198]

Cornblatt BA, Carrion RE, Addington J, Seidman L, Walker EF, Cannon TD, Cadenhead KS, McGlashan TH, Perkins DO, Tsuang MT, Woods SW, Heinssen R, Lencz T. Risk Factors for Psychosis: Impaired Social and Role Functioning. Schizophrenia Bulletin. 2011

Cornblatt BA, Carrion RE, Addington J, Seidman L, Walker EF, Cannon TD, Cadenhead KS, McGlashan TH, Perkins DO, Tsuang MT, Woods SW, Heinssen R, Lencz T. Risk factors for psychosis: Impaired social and role functioning. Schizophrenia Bulletin. 2012; 38:1247-1257. [PubMed: 22080497]

Davidson M, Reichenberg A, Rabinowitz J, Weiser M, Kaplan Z, Mordehai M. Behavioral and intellectual markers for schizophrenia in apparently healthy male adolescents. American Journal of Psychiatry. 1999; 156:1328-1335. [PubMed: 10484941]

Done DJ, Crow TJ, Johnstone EC, Sacker A. Childhood antecedents of schizophrenia and affective illness: Social adjustment at ages 7 and 11. British Medical Journal. 1994; 309:699-703. [PubMed: 7950522]

Dragt S, Nieman DH, Veltman D, Becker HE, van de Fliert R, de Haan L, Linszen DH. Environmental factors and social adjustment as predictors of a first psychosis in subjects at ultra high risk. Schizophrenia Research. 2011; 125:69-76. [PubMed: 20884179]

First, MB.; Spitzer, RL.; Gibbon, M.; Williams, JBW. Structured Clinical Interview for DSM-IV Axis I Disorders, Patient Edition, January 1995 FINAL. SCID-I/P Version 2.0. Biometrics Research Department, New York State Psychiatric Institute; New York: 1995.

Haas GL, Sweeney JA. Premorbid and onset features of first-episode schizophrenia. Schizophrenia Bulletin. 1992; 16:373-386. [PubMed: 1411328]

Häfner H, Loffler W, Maurer K, Hambrecht M, an der Heiden W. Depression, negative symptoms, social stagnation and social decline in the early course of schizophrenia. Acta Psychiatrica Scandinavica. 1999; 100:105-118. [PubMed: 10480196] 
Haim R, Rabinowitz J, Bromet E. The relationship of premorbid functioning to illness course in schizophrenia and psychotic mood disorders during two years following first hospitalization. The Journal of Nervous and Mental Disease. 2006; 194:791-795. [PubMed: 17041293]

Hans S, Marcus J. A process model for the development of schizophrenia. Psychiatry. 1987; 50:361370. [PubMed: 3423161]

Hawkins KA, McGlashan TH, Quinlan D, Miller TJ, Perkins DO, Zipursky RB, Addington J, Woods SW. Factorial structure of the Scale of Prodromal Symptoms. Schizophr Res. 2004; 68:339-347. [PubMed: 15099615]

Hoffman RE. A social deafferentation hypothesis for induction of active schizophrenia. Schizophrenia Bulletin. 2007; 33:1066-1070. [PubMed: 17631618]

Johnstone E, Ebmeier KP, Miller P, Owens DGC, Lawrie SM. Predicting schizophrenia: findings from the Edinburgh high-risk study. British Journal of Psychiatry. 2005; 186:18-25. [PubMed: 15630119]

Jones P, Rodgers B, Murray R, Marmot M. Child developmental risk factors for adult schizophrenia in the British 1946 birth cohort. The Lancet. 1994; 344:1398-1402.

Kaufman J, Birmaher B, Brent D, Rao U, Flynn C, Moreci P, Williamson D, Ryan N. Schedule for Affective Disorders and Schizophrenia for School-Age Children-Present and Lifetime Version (KSADS-PL): initial reliability and validity data. Journal of the American Academy of Child and Adolescent Psychiatry. 1997; 36:980-988. [PubMed: 9204677]

Kraemer HC, Blasey CM. Centring in regression analyses: A strategy to prevent errors in statistical inference. International Journal of Methods in Psychiatric Research. 2004; 13:141-151. [PubMed: 15297898]

Kraepelin, E. Dementia Praecox and Paraphrenia. 1971 reprint ed.. Robert E. Krieger Publishing Co. Inc.; Huntington, NY: 1919.

Kwapil TR. Social anhedonia as a predictor of the development of schizophrenia-spectrum disorders. Journal of Abnormal Psychology. 1998; 107:558-565. [PubMed: 9830243]

Larsen TK, McGlashan TH, Johannessen JO, Vibe-Hansen L. First-episode schizophrenia: II. Premorbid patterns by gender. Schizophrenia Bulletin. 1996; 22:257-269. [PubMed: 8782285]

Lemos S, Vallina O, Fernandez P, Ortega JA, Garcia P, Gutierrez A, Garcia A, Bobes J, Miller T. Predictive validity of the Scale of Prodromal Symptoms (SOPS). Actas Espanolas De Psiquiatria. 2006; 34:216-223. [PubMed: 16823681]

Lencz T, Smith CW, Auther A, Correll CU, Cornblatt B. Nonspecific and attenuated negative symptoms in patients at clinical high-risk for schizophrenia. Schizophrenia Research. 2004; 68:37-48. [PubMed: 15037338]

Levitt JJ, O'Donnell BF, McCarley RW, Nestor PG, Shenton ME. Correlations of premorbid adjustment in schizophrenia with auditory event-related potential and neuropsychological abnormalities. American Journal of Psychiatry. 1996; 153:1347-1349. [PubMed: 8831448]

MacBeth A, Gumley A. Premorbid adjustment, symptom development and quality of life in first episode psychosis: A systematic review and critical reappraisal. Acta Psychiatrica Scandinavica. 2008; 117:85-99. [PubMed: 18081922]

Mason O, Startup M, Halpin S, Schall U, Conrad A, Carr V. Risk factors for transition to first episode psychosis among individuals with 'at-risk mental states'. Schizophrenia Research. 2004; 71:227237. [PubMed: 15474894]

McClellan J, Breiger D, McCurry C, Hlastala SA. Premorbid functioning in early-onset psychotic disorders. Journal of American Academy of Child Adolescent Psychiatry. 2003; 42:666-672.

McGlashan, T.; Walsh, B.; Woods, SW. The Psychosis-Risk Syndrome: Handbook for Diagnosis and Follow-Up. Oxford University Press; USA: 2010.

Miller TJ, McGlashan TH, Rosen JL, Cadenhead K, Cannon T, Ventura J, McFarlane W, Perkins DO, Pearlson GD, Woods SW. Prodromal assessment with the structured interview for prodromal syndromes and the scale of prodromal symptoms: predictive validity, interrater reliability, and training to reliability. Schizophrenia Bulletin. 2003; 29:703-715. [PubMed: 14989408]

Miller TJ, McGlashan TH, Rosen JL, Somjee L, Markovich PJ, Stein K, Woods SW. Prospective diagnosis of the initial prodrome for schizophrenia based on the Structured Interview for 
Prodromal Syndromes: preliminary evidence of interrater reliability and predictive validity. American Journal of Psychiatry. 2002; 159:863-865. [PubMed: 11986145]

Mueser, KT.; Bellack, AS. Social skills and social functioning in schizophrenia. In: Mueser, KT.; Tarrier, N., editors. Handbook of Social Functioning in Schizophrenia. Allyn \& Bacon; Needham Heights, MA: 1998. p. 79-96.

Niemi LT, Suvisaari JM, Haukka JK, Lonnqvist JK. Childhood predictors of future psychiatric morbidity in offspring of mothers with psychotic disorder: Results from the Helsinki high-risk study. British Journal of Psychiatry. 2005; 186:108-114. [PubMed: 15684232]

Olin S-CS, Mednick SA, Cannon T, Jacobsen B, Parnas J, Schulsinger F, Schulsinger H. School teacher ratings predictive of psychiatric outcome 25 years later. British Journal of Psychiatry. 1998; 172:7-13. [PubMed: 9534824]

Pinkham AE, Penn DL, Perkins DO, Graham KA, Siegel M. Emotion perception and social skill over the course of psychosis: A comparison of individuals "at-risk" for psychosis and individuals with early and chronic schizophrenia spectrum illness. Cognitive Neuropsychiatry. 2007; 12:198-212. [PubMed: 17453901]

Piskulic D, Addington J, Cadenhead KS, Cannon TD, Cornblatt BA, Heinssen R, Perkins DO, Seidman LJ, Tsuang MT, Walker EF, Woods SW, McGlashan TH. Negative symptoms in individuals at clinical high risk of psychosis. Psychiatry Research. 2012; 196:220-224. [PubMed: 22445704]

Rabinowicz J, Reichenberg A, Weiser M, Mark M, Kaplan Z, Davidson M. Cognitive and behavioural functioning in men with schizophrenia both before and shortly after first admission to hospital: Cross-sectional analysis. British Journal of Psychiatry. 2000; 177:26-32. [PubMed: 10945084]

Reichenberg A, Weiser M, Rabinowicz J, Caspi A, Schmeidler J, Mark M, Kaplan Z, Davidson M. A population-based cohort study of premorbid intellectual, language, and behavioral functioning in patients with schizophrenia, schizoaffective disorder, and nonpsychotic bipolar disorder. American Journal of Psychiatry. 2002; 159:2027-2035. [PubMed: 12450952]

Ruhrmann S, Schultze-Lutter F, Salokangas RKR, Heinimaa M, Linszen D, Dingemans P, Birchwood M, Patterson P, Juckel G, Heinz A, Morrison A, Lewis S, Graf von Reventlow H, Klosterkotter J. Prediction of psychosis in adolescents and young adults at high risk: Results from the Prospective European Prediction of Psychosis Study. Archives of General Psychiatry. 2010; 67:241-251. [PubMed: 20194824]

Saracco-Alvarez R, Rodriguez-Verdugo S, Garcia-Anaya M, Fresan A. Premorbid adjustment in schizophrenia and schizoaffective disorder. Psychiatry Research. 2009; 165:234-240. [PubMed: 19162333]

Schiffman J, Walker E, Ekstrom M, Schulsinger F, Sorensen H, Mednick S. Childhood videotaped social and neuromotor precursors of schizophrenia: A prospective investigation. American Journal of Psychiatry. 2004; 161:2021-2027. [PubMed: 15514402]

Silverstein ML, Mavrolefteros G, Turnbull A. Premorbid factors in relation to motor, memory, and executive functions deficits in adult schizophrenia. Schizophrenia Research. 2003; 61:271-280. [PubMed: 12729879]

Strauss JS, Carpenter WT. The prediction of outcome in schizophrenia: I. Characteristics of outcome. Archives of General Psychiatry. 1972; 27:739-746. [PubMed: 4637891]

Strous RD, Alvir JMJ, Robinson D, Gal G, Sheitman B, Chakos M, Lieberman JA. Premorbid functioning in schizophrenia: Relation to baseline symptoms, treatment response, and medication side effects. Schizophrenia Bulletin. 2004; 30:265-278. [PubMed: 15279045]

Tarbox SI, Addington J, Cadenhead K, Cannon TD, Cornblatt B, Perkins D, Seidman LJ, Tsuang MT, Walker E, Heinssen R, McGlashan T, Woods SW. Premorbid functional development and conversion to psychosis in clinical high-risk youth. Development and Psychopathology. 2013; 25:1173-1188.

Tarbox SI, Brown LH, Haas GL. Diagnostic specificity of poor premorbid adjustment: Comparison of schizophrenia, schizoaffective disorder, and mood disorder with psychotic features. Schizophrenia Research. 2012; 141:91-97. [PubMed: 22858353]

Tarbox SI, Pogue-Geile MF. Development of social functioning in preschizophrenia children and adolescents: a systematic review. Psychological Bulletin. 2008; 34:561-583. [PubMed: 18605820] 
Thompson A, Nelson B, Yung A. Predictive validity of clinical variables in the "at risk" for psychosis population: International comparison with results from the North American Prodrome Longitudinal Study. Schizophrenia Research. 2011; 126:51-57. [PubMed: 21035313]

Uzelac S, Jaeger J, Berns S, Gonzales C. Premorbid adjustment in bipolar disorder: Comparison with schizophrenia. Journal of Nervous and Mental Disease. 2006; 194:654-658. [PubMed: 16971816]

Velthorst E, Nieman DH, Becker HE, van de Fliert R, Dingemans PM, Klaassen R, de Haan L, van Amelsvoort T, Linszen DH. Baseline differences in clinical symptomatology between ultra high risk subjects with and without a transition to psychosis. Schizophrenia Research. 2009; 109:60-65. [PubMed: 19272756]

Watt NF. Patterns of childhood social development in adult schizophrenics. Archives of General Psychiatry. 1978; 35:160-165. [PubMed: 623502]

Willinger U, Heiden AM, Meszaros K, Formann AK, Aschauer HN. Neurodevelopmental schizophrenia: Obstetric complications, birth weight, premorbid social withdrawal and learning disabilities. Neuropsychobiology. 2001; 43:163-169. [PubMed: 11287795]

Woods SW, Addington J, Cadenhead KS, Cannon TD, Cornblatt BA, Heinssen R, Perkins DO, Seidman LJ, Tsuang MT, Walker EF, McGlashan TH. Validity of the Prodromal Risk Syndrome for first psychosis: Findings from the North American Prodrome Longitudinal Study. Schizophrenia Bulletin. 2009; 35:894-908. [PubMed: 19386578]

Yung AR, Phillips LJ, Yuen HP, Francey SM, McFarlane CA, Hallgren M, McGorry PD. Psychosis prediction: 12-month follow up of a high-risk ("prodromal") group. Schizophrenia Research. 2003; 60:21-32. [PubMed: 12505135]

Yung AR, Phillips LJ, Yuen HP, McGorry PD. Risk factors for psychosis in an ultra high-risk group: psychopathology and clinical features. Schizophrenia Research. 2004; 67:131-142. [PubMed: 14984872] 


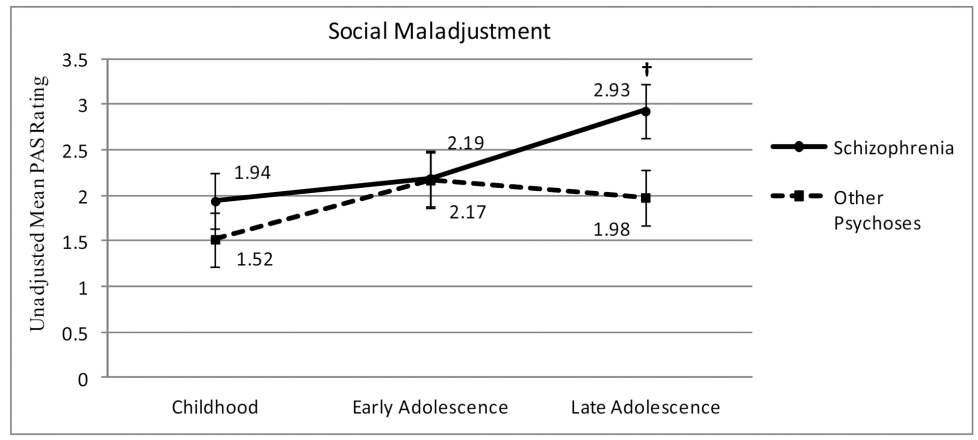

Note: Figure presents unadjusted mean PAS ratings, not controlling for prior maladjustment; data labels for schizophrenia outcome diagnosis are positioned above data points; labels for other psychotic disorders are below; schizophrenia $n=28$, other psychotic disorders $n=26$.

$\dagger$ Schizophrenia > other psychoses: $O R=1.80, p=.069$.

Figure 1.

Social maladjustment across development: Conversion to schizophrenia vs. other psychotic disorders 


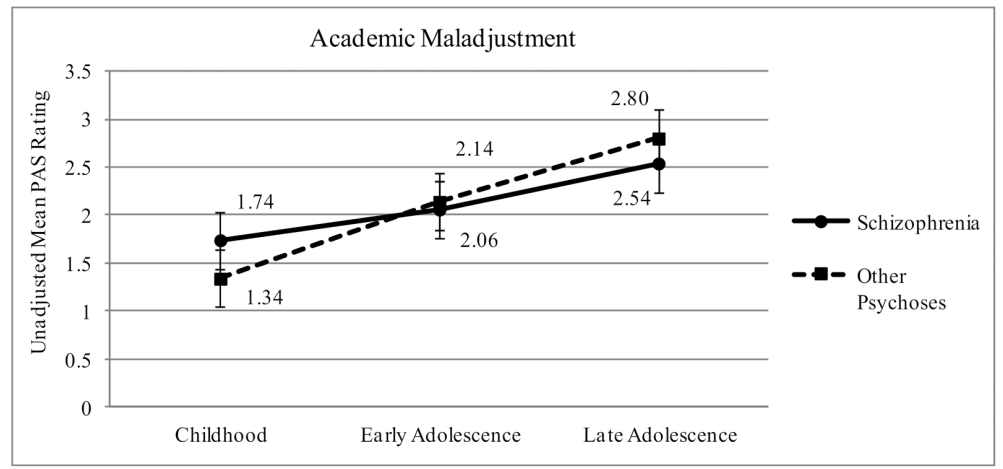

Note: Figure presents unadjusted mean PAS ratings, not controlling for prior maladjustment; schizophrenia $n=28$, other psychotic disorders $n=26$.

Figure 2.

Academic maladjustment across development: Conversion to schizophrenia vs. other psychotic disorders 


\section{Table 1}

Demographic characteristics by conversion diagnosis

Demographic characteristics

\begin{tabular}{|c|c|c|c|c|c|c|c|c|}
\hline \multirow[b]{3}{*}{ Conversion Diagnosis $(n)$} & \multicolumn{8}{|c|}{ Demographic characteristics } \\
\hline & \multicolumn{5}{|c|}{ Baseline Assessment } & \multicolumn{3}{|c|}{ Conversion Assessment } \\
\hline & $\begin{array}{l}\text { Age, yrs: } \\
\text { mean (sd) }\end{array}$ & Sex: \% male & $\begin{array}{l}\text { Race: \% } \\
\text { EuAm/\% } \\
\text { AfAm }\end{array}$ & $\begin{array}{l}\text { Education, } \\
\text { yrs: mean } \\
\text { (sd) }\end{array}$ & $\begin{array}{l}\text { Parent } \\
\text { HS: \% } \\
\text { both }^{a}\end{array}$ & $\begin{array}{l}\text { Prodrome } \\
\text { duration, } \\
\text { yrs: mean } \\
\text { (sd) }\end{array}$ & $\begin{array}{l}\text { Age, yrs: } \\
\text { mean (sd) }\end{array}$ & $\begin{array}{l}\text { Education, } \\
\text { yrs: mean } \\
\text { (sd) }\end{array}$ \\
\hline Total (54) & $19.7(3.4)$ & 57.4 & $72.2 / 13.0$ & $11.7(2.1)$ & 57.4 & $1.4(2.6)$ & $20.7(3.5)$ & $12.0(2.1)$ \\
\hline Schizophrenia (28) ${ }^{b}$ & $19.8(3.2)$ & 64.3 & $67.9 / 14.3$ & $11.4(2.2)$ & 57.1 & $1.1(1.7)$ & $20.6(3.3)$ & $11.9(1.9)$ \\
\hline Other psychoses $(26)^{c}$ & $19.6(3.7)$ & 50.0 & $76.9 / 11.5$ & $12.1(2.1)$ & 57.7 & $1.9(3.6)$ & $20.8(3.7)$ & $12.2(2.3)$ \\
\hline
\end{tabular}

${ }^{a}$ Both parents completed high school;

$b_{\text {Includes schizophrenia and schizophreniform disorder. }}$

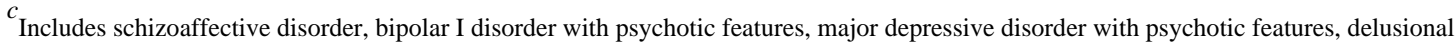
disorder, brief psychotic disorder, and psychotic disorder not otherwise specified. 
Table 2

Social premorbid maladjustment and prediction of conversion to schizophrenia vs. other psychotic disorders

\begin{tabular}{llllll} 
& \multicolumn{5}{c}{ Parameter Estimates } \\
\cline { 2 - 6 } Predictor Added at Each Step & $\beta$ & SE $\boldsymbol{\beta}$ & $\boldsymbol{P}$ & OR & $\mathbf{9 5 \%} \boldsymbol{C I}$ \\
\hline Step 1 & & & & & \\
\hline $\begin{array}{l}\text { Childhood social maladjustment } \\
\text { Step 2 }\end{array}$ & 0.23 & 0.27 & 0.389 & 1.26 & $0.75-2.13$ \\
\hline $\begin{array}{l}\text { Early adolescent social maladjustment }^{a} \\
\text { Step 3 }\end{array}$ & -0.23 & 0.45 & 0.615 & 0.80 & $0.33-1.92$ \\
\hline Late adolescent social maladjustment $^{b}$ & 1.39 & 0.64 & 0.029 & 4.02 & $1.15-14.06$ \\
\hline
\end{tabular}

Note: Step-wise logistic regression analysis performed using centered, standardized PAS ratings; Diagnostic outcome coded schizophrenia $=1$, other psychotic disorders $=0$; schizophrenia, $n=28$; other psychotic disorders, $n=26$; Intercept included at each step.

${ }^{a}$ Controlling for childhood social maladjustment.

${ }^{b}$ Controlling for childhood and early adolescent social maladjustment. 


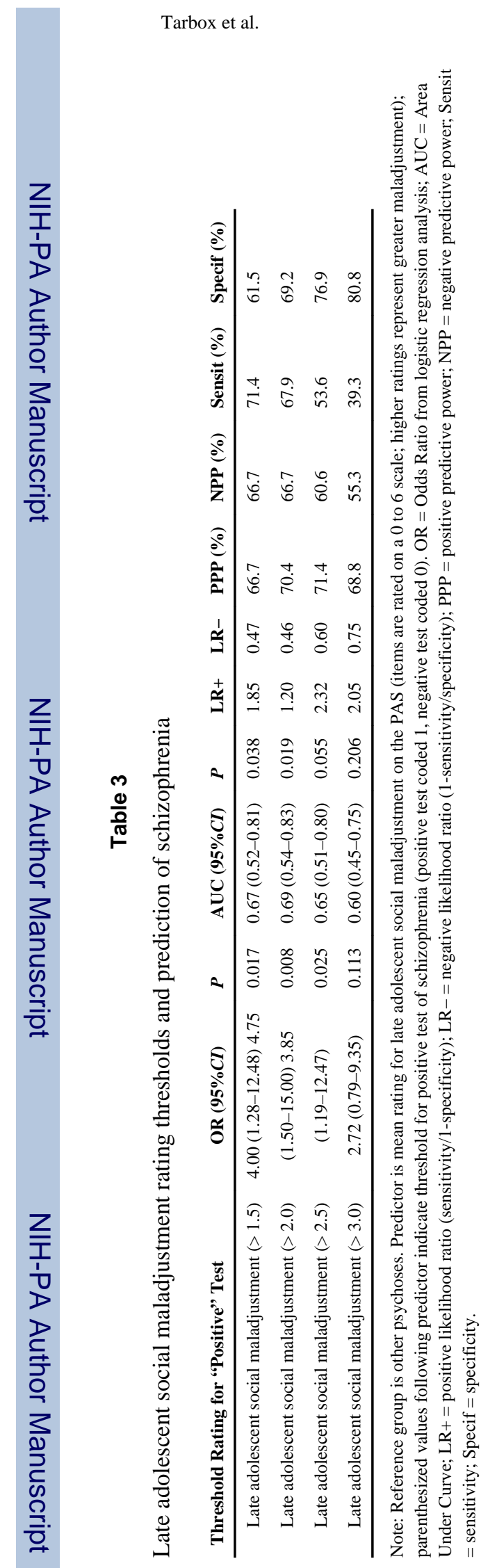

Psychiatry Res. Author manuscript; available in PMC 2015 January 30. 


\section{Table 4}

Academic premorbid maladjustment and prediction of conversion to schizophrenia vs. other psychotic disorders

\begin{tabular}{lllllll} 
& \multicolumn{7}{c}{ Parameter Estimates } & & \\
\cline { 2 - 6 } Predictor Added at Each Step & $\beta$ & SE $\beta$ & $P$ & OR & 95\% CI \\
\hline Step 1 & $\beta$ & & & & & \\
\hline $\begin{array}{l}\text { Childhood academic maladjustment } \\
\text { Step 2 }\end{array}$ & 0.38 & 0.34 & .263 & 1.46 & $0.75-2.81$ \\
\hline $\begin{array}{l}\text { Early adolescent academic maladjustment } \\
\text { Step 3 }\end{array}$ & -0.75 & 0.59 & .203 & 0.47 & $0.15-1.50$ \\
\hline $\begin{array}{l}\text { Late adolescent academic maladjustment } \\
b\end{array}$ & -0.16 & 0.52 & .761 & 0.85 & $0.31-2.38$ \\
\hline
\end{tabular}

Note: Step-wise logistic regression analysis performed using centered, standardized PAS ratings; Diagnostic outcome coded schizophrenia = 1 , other psychotic disorders $=0$; Schizophrenia, $n=28$; Other psychotic disorders, $n=26$; Intercept included at each step.

${ }^{a}$ Controlling for childhood academic maladjustment.

${ }^{b}$ Controlling for childhood and early adolescent academic maladjustment. 


\section{Table 5}

Social premorbid maladjustment controlling for academic premorbid maladjustment: prediction of conversion to schizophrenia vs. other psychotic disorders

\begin{tabular}{llllll} 
& \multicolumn{3}{c}{ Parameter Estimates } & & \\
\cline { 2 - 6 } Predictors Added at Each Step & $\beta$ & SE $\beta$ & $\boldsymbol{P}$ & OR & 95\% CI \\
\hline Step 1 & & & & & \\
\hline Childhood academic maladjustment & 0.27 & 0.40 & .496 & 1.31 & $0.60-2.86$ \\
Childhood social maladjustment & 0.16 & 0.32 & .625 & 1.17 & $0.62-2.20$ \\
Step 2 & & & & & \\
\hline Early adolescent academic maladjustment & -0.66 & 0.61 & .280 & 0.52 & $0.16-1.72$ \\
Early adolescent social maladjustment & -0.23 & 0.49 & .631 & 0.79 & $0.31-2.05$ \\
Step 3 $b$ & & & & & \\
\hline Late adolescent academic maladjustment & -0.69 & 0.62 & .264 & 0.50 & $0.15-1.68$ \\
Late adolescent social maladjustment & 1.73 & 0.70 & .014 & 5.64 & $1.43-22.34$ \\
\hline
\end{tabular}

Note: Step-wise logistic regression analysis performed using centered, standardized PAS ratings; Diagnostic outcome coded schizophrenia $=1$, other psychotic disorders $=0$; Schizophrenia, $n=28$; Other psychotic disorders, $n=26$; Intercept included at each step.

${ }^{a}$ Controlling for childhood social and academic maladjustment.

${ }^{b}$ Controlling for childhood and early adolescent social and academic maladjustment. 